Doing the Right Thing: Some notes on the control of research in British criminology

Simon Winlow and Fiona Measham

\title{
Abstract
}

In this chapter we discuss some of the problems associated with developing forms of ethical oversight in the field of criminology and criminal justice. We argue that the core concerns of institutional ethics committees are inextricably bound up with the logic of the market. The ongoing marketization of the university is, quite clearly, affecting the production of knowledge, and institutional ethics committees now possess an unstated and unacknowledged desire to defend the institution from litigation and reputational damage. This desire now exhorts a subtle but powerful influence upon the deliberations of institutional ethics committees. Using our own research backgrounds and engagement with institutional ethics committees as a foundation for our critique, we argue that ethnography, and in situ social research more generally, must be protected from those forces that would seek to formalise, sanitise and control it.

Key points:

1. Institutional ethics committees now function to defend the institution from litigation and reputational damage.

2. The consideration of 'ethics' - properly defined - actually plays a marginal role in the deliberations of ethics committees. 
3. This situation is dissuading, or actively preventing, some social scientists from utilising their preferred forms of research.

4. The transformation of the ethics committee, and its role in dissuading some forms of qualitative research, is already affecting the production of criminological knowledge.

\section{Introduction: Context}

Criminology has grown enormously in recent years. In Britain the discipline has also recently undergone a benchmarking exercise that sought to apply some order and rigor to the materials covered within the country's undergraduate criminology programmes. Criminology, once a rag-tag discipline populated by academics with a general interest in crime who had migrated to this new shared space from a broad variety of fields - often bringing with them concepts and methodologies from across the social sciences and humanities - has become more organised and institutionalised, and its once porous and hazily defined boundaries appear to have hardened. In Britain, of course, undergraduate criminology degrees have been around for some time, and many younger professional criminologists have passed through undergraduate criminology programmes. Their educational experience is often quite specific to this field. It is clear that we have already passed through a period in which our disciplinary history has been codified and reified. It is now endlessly reproduced in textbooks, and no longer argued about to any great extent. We might also suggest that with every passing year the discipline of criminology displays less and less interest in theory-building and a growing preoccupation with empirical data collection, criminal justice practice, crime prevention and the management of offenders (Hall et al, 2008). Thorough-going critical accounts of criminal 
motivations and the background to crime certainly form a smaller part of the discipline than they once did (Hall, 2012). Political and theoretical truth projects have also declined quite markedly (Winlow, 2012), and we might tentatively suggest this decline is closely connected to a growth in careerism in the academy generally and the ubiquity of abstract empiricism within our discipline specifically (Currie, 2007; Matthews, 2009).

At first glance the discipline appears to be splitting apart into competing factions. However, the surface factionalism of criminology is not all it seems. There remains a good deal of accord, even between factions that have historically displayed a degree of hostility towards each other. There may be brief skirmishes here and there but a genuine clash of ideologies no longer takes place on the field of criminology. This is a shame, because without ideological commitment there can be no genuine dialectical movement. British criminology has instead adopted something of a bunker mentality. Critical criminologists fire the odd salvo at administrative criminologists but they cause no damage and nothing changes. Instead, each sub-field of criminology appears strangely self-sufficient and there is less and less intellectual engagement between them. Those on the left complain about the power and privilege of those on the right, but in fact only a tiny number of British criminologists can be identified as being adherents of right-wing politics or philosophy. In our times it is the philosophy of liberalism that has triumphed, and the monumental scale of its triumph has ensured that liberalism has lost much of its original philosophical substance (see Bell, 2014; Hall, 2012). It now stretches from the hard-core Randian libertarianism of the right to the interventionist social liberalism of the left, and criticism of the overbearing state is as common of criminology's left wing as it is on its right (Matthews, 2014; Winlow et al, 2015). It seems that, for the time being, all intellectual skirmishes in criminology will take place on this 'post-ideological' landscape (see Horsley, 2014). This stark fact should encourage us to acknowledge that beneath our 
discipline's surface discord lie a range of shared, if often disavowed, political and philosophical commitments that bond the discipline together and inform its present condition.

It is entirely possible that the reader will disagree with this brief and partial assessment indeed, we believe that such disagreements should now be aired quite openly in the hope of prompting a productive interchange about the future of our discipline - but what we can say without fear of contradiction is that criminology is at a crossroads. In our institutions we remain locked into hectic schedules of teaching, research and administration. We tend to focus on impending deadlines and the range of tasks that structure our working week. As space for quiet contemplation and abstract thought diminishes, we tend not to be greatly preoccupied with the present trajectory of our discipline or its intellectual health and vitality. However, despite the growing gap between the institutional lives of criminologists and the broader national and international academic discipline of criminology, there appears to be a growing recognition that all is not well and that the future of our discipline may not be as rosy as we once imagined.

The drive to generate research income and the considerable pressures of the Research Excellence Framework are transforming the working lives of criminologists across Britain. The 'publish or perish' ethos may have contributed to the expansion of criminology, especially in terms of the breadth of topics covered and the mass of data produced, but it has also meant that criminologists have less and less time to keep abreast of new developments in the field. We are writing more and reading less it seems. There is now a huge variety of journals on the market and there has been a staggering growth in the number of criminology books published each year. However, there is little sense that a growth in quantity has led to a 
growth in quality, or that, as the discipline steps gingerly into the twenty-first century, new truths are being revealed to us.

\section{Throwing out the baby with the bath water}

We want to focus upon one small aspect of this general disciplinary inertia. It is clear that empirical research has edged out theory to occupy the core of our discipline. Criminology is now teeming with data, and almost all of the bespoke subfields that make up our disciplinary mosaic have benefitted from the turn towards empirical research. But despite the considerable successes of our empirical research projects, there is a growing sense among social scientists - and those orientated to qualitative research in particular - that their work is now being impeded by institutional systems of ethical governance. What, we must ask, has changed in research governance, and why is there a growing antagonism among researchers towards ethics committees?

We should note that, as our discipline began to establish itself during the final third of the twentieth century, it rather thoughtlessly followed other social science disciplines in adopting models of methodological rigor that owe a great deal to the core methodological concerns of the hard sciences (Smart, 2003). Research practice since those days has changed hardly at all, but ethical oversight of research practice now seems far tougher and more demanding. Perhaps we should conclude that this is no bad thing if problematic research projects are no longer slipping through the net, and rigorous oversight is keeping the harms of the research process to an absolute minimum. However, despite the nature of our discipline, criminology has not proven to be any more ethically problematic than other disciplines in the social sciences. Our history is not littered with cases of unethical research practice, and it is not 
immediately clear that the toughening of ethical governance has been a necessary measure that has prevented problematic research conduct in criminology (Winlow and Hall, 2012).

It makes sense to conclude that forces external to the discipline have prompted this toughening. Under the standard rubric of 'professionalisation', the market imperatives that have quickly moved to the very heart of the British university system appear, in a very subtle and indirect manner, to have prompted our ethics committees to tighten the net in order to protect our institutions from litigation and reputational damage. A dull bureaucratised pragmatism has taken over and the positive substance that must be retained is seeping out of the system at an alarming rate, leaving only a creaking and often alienating administrative process that frequently blocks important, challenging or cutting edge research, or places significant impediments in front of researchers keen to engage with criminals, deviants or marginalised populations in a reasonably naturalistic manner (see Smith, 2014; Ancrum, 2012). And this is not just a system that impedes working criminologists. Postgraduate and undergraduate students are also affected. Often our most talented and intellectually engaged undergraduate students are very keen to leave behind the confines of the university and head out into the real world to gather their own data for their final year dissertation. In many cases this proves to be impossible. The risk averse nature of the institutional ethics committee inevitably leads talented students to opt for library-based study, which in turn makes the emphasis that is placed on research methods teaching all the more mystifying. All too rarely do students get a chance to conduct their own qualitative research, and even those who progress to postgraduate study quickly discover that it is now very difficult to gain approval for research projects that involve actually meeting and talking to criminals and deviants in non-institutional settings. 
Let us be clear: we are not claiming that ethnography and qualitative research are on the verge of extinction, or that they will play an increasingly marginal role in the production and reproduction of criminological knowledge as the discipline moves forward. Rather, we are claiming that these methodologies are increasingly deprived of their traditional substance. To us, and other qualitative researchers we have consulted, it seems that something is missing, and it seems to be missing because ethics committees appeared dedicated to minimising risk and sanitising research processes that, in truth, did not need to be sanitised. Many field researchers complain about the ethics committee's drive to control interaction and engagement between the researcher and the researched, and its drive to set firm limits and how such interactions are brought into being and how they develop over time. Qualitative researchers - indeed all researchers who place themselves in what might appear, to the ethics committee, to be 'risky settings' that might precipitate 'risky encounters' - are increasingly over-policed, and researchers are understandably keen to avoid breaching the rules handed down by ethics committees, and increasingly cautious about their engagement with populations considered in some way 'deviant'. The ethics committee's drive to professionalise research practice, monitor interaction and protect against harm has led to the erection of barriers between the researcher and the research subject. Quite clearly, these barriers can be negotiated and valuable research can still be done, but we should not dismiss the possibility that the intimacies that existed between the researcher and the research subject in earlier epochs are a good deal harder to construct and maintain these days. The drive to rid the discipline of unethical research practice needs to be placed in an appropriate context, and we must avoid meekly accepting ethical governance in its present form as a necessary intervention that will eventually lead to beneficial outcomes. Instead we should be bold enough to contemplate a more disturbing reality in which we appear to be throwing out the baby with the bathwater. 


\section{The Practice of Ethics Committees}

Within our discipline there is a broad agreement that steps should be taken to ensure that our research practice does not harm participants and that researchers are not exposed to unnecessary danger (see, for example, the British Society of Criminology, 2006), but many criminologists also feel these important considerations are no longer of paramount importance to our institutional ethics committees. Other concerns that appear to have little to do with 'ethics' have begun to sneak in and progressively work their way closer to the centre, and the traditional activities associated with ethical oversight have been marginalised or forgotten entirely. When presenting our own work to institutional ethics committees, we have encountered there what might be termed a lawyer's mentality that appears to operate within an essentially administrative and managerialist culture that encourages the various academics who gather under its auspices to grind their way through the agenda while sifting and sorting research proposals into piles of 'the approved' and 'the disapproved'; the consideration of ethics, properly understood, nowhere to be seen. Can the committee envisage a situation in which the researcher witnesses or becomes aware of criminal acts? Is there any possibility that the research might threaten an individual's legal entitlements or those of a business entity or organisation? If there is a chance that research might be conducted in or on privatelyowned property, have the necessary permissions been sought? Is there any chance that this research might threaten the reputation of the university? These are the questions that appear most often to inform the committee's deliberations.

In our view, the rubric of 'informed consent' appears to have become something of a panacea for ethics committees, or at least those forced to engage with the thorny problems that accompany qualitative and in situ research proposals in the field of criminology. Forms 
outlining the aims and outcomes of the research project, and the rights of the research participant in relation to it, must be signed by each contact before data-gathering can commence. On the surface of things we might, with some justification, claim that the increased focus upon 'informed consent' reflects a growing concern for the rights of research participants. However, some qualitative researchers we have spoken to doubt that the requirements of 'informed consent' are truly altruistic and reflect a genuine desire to ensure that no harm comes to research participants. Instead, they take the view that beneath this surface positivity lies a darker motivation. This motivation is never fully revealed, but its influence can be detected across the new terrain of research management. The pragmatism of the market, and its concern with the bottom line, is subtly working its magic, disturbing traditional cultures and enforcing new logics of managerialism, professionalization and oversight. Beneath the surface of concern for participants lies a powerful desire to ensure that nothing returns to harm the interests of the institution.

What, we must ask, are the institutional and ideological roles of ethics committees, and how are ethics committees shaping the research produced within our discipline? How might the new rigors of ethical oversight be affecting the production of criminological knowledge? How do ethics committees reach their decisions, and do forthright discussions of ethics properly understood - play any role at all in these deliberations? Who sits on ethics committees, and how might the background, fieldwork experience and social identities of members inform the practice of these committees? Are members 'socialised' into the committee's normative practice, and, as they become inured to this new reality, might the bonds that connect committee members to more esoteric - but hugely important - questions about what is good and right begin to loosen? Does the ethics committee member, keen to get out of another boring meeting as quickly as possible, simply reapply an already-in-place logic 
rooted in expediency, compliance with the law and protecting the institution from any kind of negative attention? Has the contemplation of ethics been formalised and bureaucratised or has the contemplation of ethics been entirely withdrawn, replaced only with a malign institutional pragmatism?

What concerns us most is that 'ethics', and 'ethical governance', have gradually become a system of external control that enforces a prescribed set of rules that relate to research practice. Inevitably, when 'ethics' exists as an external - rather than an internal - system of governance, the researcher is forced to engage with it as such. Submitting a research proposal to an ethics committee is relegated to the status of a mere administrative task, a hurdle we must overcome before the researcher is allowed to get on with the real work. This gradual transformation is far more important and negativistic than we might imagine. The ethics committee as a system of governance, a regulator that determines what is and is not allowed, encourages researchers to engage with it in an essentially sociopathic manner. The researcher is encouraged to say the right things and tick the right boxes, to acknowledge the rules and promise to abide by them. The researcher must ask, what will the ethics committee make of this or that? Does my proposal break the rules in any way? What should I write in my research proposal that might encourage the committee to look favourably upon it? Of course, there has always been a clear division between the initial research proposal and the actual lived research project, but as the researcher becomes increasingly conversant with the demands of the ethics committee, and learns how to 'play the game', this division becomes increasingly stark. The research proposal is simply an administrative task that must be completed, and the researcher knows that it is in his or her best interests to present research plans in a particular way. Like the stereotypical sociopath, the researcher knows the rules, and knows that it is in his or her interests to live by them. However, like the sociopath, these 
rules remain only external rules that are imposed upon and seek to regulate the subject. They are not absorbed or used as a determining structure in our mental life, forming part of what we call our conscience, the 'voice in our heads' that constantly reminds us to abide by the rules of our community. When our postgraduate students contact us about ethical matters, they often pitch their questions in this rather disconcerting manner. What will the ethics committee say about this or that? What are the 'rules' when faced with this particular kind of ethical problem? Of course, during research, when one is faced with challenging events, the proper response is to think and respond in relation to one's own conscience and embodied ethics. One should ask, is such a thing right or wrong, rather than, what are the rules that govern research practice when faced with such a dilemma? Of course, in the well-adjusted individual, all of this should happen immediately. We should respond morally to the world as we encounter it. We should think, what is the right thing to do, and then do it, rather than suspending judgement until one has had an opportunity to consult the rules and regulations. A worrying gap is opening up between the ethics committee, which acts as a regulatory agency, and our own research practice, which of course should be constantly monitored by our own embodied ethics, our own independent sense of what is right and wrong. In order to advance this argument, it seems necessary to step back a little and consider other issues connected to the governance of research practice in criminology.

\section{Ethnography must be defended}

What do we mean by the phrase 'value free' social research? How can social research be 'value free' and at the same time completely in-keeping with value-laden conceptions of appropriate research conduct (see Ancrum, 2012)? How can we remain set apart from the world while at the same time subject to normative models of moral social engagement (see Smith, 2014; Ellis, 2015)? Of course, during methods training criminologists are instructed to 
remain objective and value-free despite the fact that it is impossible for a human being to accomplish this task without lapsing into psychosis (see Gouldner, 1962; Roberts, 1981; Stanley and Wise, 2002). Political and ideological commitments are believed to contaminate our empirical studies. Because we cannot dispense with such commitments, we are forced to deny their existence and pretend that, upon entering the field, we were magically able to transform ourselves into apolitical and ahistorical automatons able to appraise reality objectively, and, when data-gathering is complete, that we possess the magical ability to free ourselves from established commitments in order to interpret our data honestly and in a way that identifies a fundamental truth free from the contaminants of our established social identities.

Criminology is a discipline that exists at the forefront of ethical condemnation. Our subject matter is inherently contentious as it references some kind of rupture in the moral, ethical or regulatory foundations of our world. Because our discipline proceeds from this base, there exists a powerful imperative to ensure that our research sticks rigidly to established ethics frameworks. Of course, in order to remain faithful to the concerns upon which the discipline was founded, we must engage with criminals of all kinds: We must speak to drug users and dealers, rapists and paedophiles, rioters and terrorists, fraudsters and racists, and many other criminal or deviant groups, and, if we remain committed to working through the complexities of motivation, drive and causation, it is beneficial to talk with our respondents in situ, in noncustodial settings and in places where they feel sufficiently relaxed, safe and willing to open up to a researcher. We must also note that the vast majority of criminals actively attempt to conceal their crimes. Even when criminals are caught and incarcerated they may continue to disguise the reality of their deeds to interested academics. Observing deviant populations in action and talking to criminals who are actively engaged in criminal markets is therefore of 
huge value. We should be fighting hard to resuscitate the dying art of ethnography, especially those forms of ethnography that seek to capture the realities of culture in action. The ethics committee's drive to regulate research practice means that increasingly only those forms of ethnography go ahead that can work in accordance with its rules. Can the ethnographer conduct informed consent procedures? Will every research participant be equipped with the knowledge to make informed decisions? Of course, observing criminals and deviants in situ opens up a host of methodological and ethical dilemmas, but rather than address these in a reasonably considered manner, the clear ideological orientation of the ethics committee is to construct hard boundaries on what is and isn't allowed, and then force researchers to live with its decisions.

Certainly, many ethnographic accounts of deviant populations operate within an essentially appreciative ideological frame (see for example, Becker, 1963; Young 1971) that encourages readers to reconsider the role of power in the construction of law and order and in social conceptions of deviance and normalcy. Perhaps we could do more to move beyond cultural appreciation and develop more realistic ethnographic accounts of criminal and deviant cultures (Hall and Winlow, 2015), but the benefits of ethnography as a method should be quite clear. Forthright, truth-seeking qualitative research is integral to the health of our discipline. The attempts made by ethics committees to regulate ethnographic research practice inevitably impact upon the data we gather. Some populations of great interest to criminologists are quite unwilling to talk honestly and openly to a researcher brandishing a recording device and official-looking documents, and this is especially true when the researcher asks for a signature and hopes to discuss the involvement of that population in crime and deviance. However, a talented and generally unencumbered ethnographer who presents herself as a fully human presence, possessed of her own identity and views and 
willing to engage in open-ended discussion, might just manage to elicit genuinely illuminating information from hard-to-reach research populations. This requires time and effort and a willingness to leave the world of the university behind. It requires the researcher to respond to the world as she encounters it rather than constantly worrying whether she has transgressed the rules. Here, the requirements handed down by the ethics committee act as a significant impediment to those forms of ethnographic research practice that used to be quite common in sociological criminology. Ethnography continues of course, but, we claim, it is vital that we wrestle with the possibility that it does so despite new regulatory measures. The ethics committee's drive to regulate research practice in order to mitigate harm brings with it a general reduction in the human intimacy that makes ethnography such a vital research methodology for the social sciences.

\section{Criminology at a crossroads}

If we are to prevent criminology's gradual slide into 'controlology' (Ditton, 1979), it seems to us important to reconnect criminology to its principle objects of crime and harm. We need to know what they are and why they occur. Already too much of our discipline is concerned with the aftermath of crime: the response of the media, the response of the police and the criminal justice system, the response of the victim and the victim's community, and so on. These things are of considerable importance, but with every passing year British criminology appears marginally less interested in the actual causes of crime and harm, as if all that can be said about such things has already been said, and so the discipline can leave behind its traditional objects in order to construct research-informed demands for more a comprehensive system of human rights and a more civilised criminal justice system (see Hall and Winlow, 2015). We should be doing all we can to encourage ambitious and energetic postgraduate students to engage with real life as it is lived by populations of interest to 
criminology. Instead we tend to treat institutional ethics committee as a regrettable inevitability. Researchers across the land complain in private but tend to go along with the process of applying for ethical clearance, despite the fact that they have little or no faith in the ethics committee to form reasonable judgements. Tales of the staggering naivety and the breath-taking stupidity of ethics committees are quite common when one broaches the topic of ethical governance with active field researchers. Almost all of the qualitative researchers we've talked to had a tale to tell. In the pages that follow we will report upon our own research experiences among criminal and deviant populations of various kinds.

Both of the authors of this paper, when about to undertake research with deviants and lawbreakers, have been repeatedly asked by members of institutional ethics committees if they intended to inform the police of any illegality they may encounter during their studies. Winlow (2001) was encouraged to use consent forms in a project that involved interviewing young men involved in the sale and distribution of cocaine and ecstasy (see also Winlow and Hall, 2006), and Measham was encouraged to use consent forms when observing clubbers consuming dance drugs (see Measham et al 2011). Amazingly, Measham was asked by her institutional ethics committee to inform the police if she saw any actual drug consumption in nightclubs populated almost entirely by people who had taken drugs. This request was particularly mindboggling, given that the police themselves were fully aware that the venue was frequented by drug-users. Indeed, the police knew about and actively supported the research, and were forward-thinking enough to see the value in research that was geared towards identifying opportunities to prevent harm. Don't cases such as this indicate that the principal concern of ethics committees is simply to enforce the rules rather than engage with individual research proposals in a reasonably intelligent fashion? Quite clearly, there often exists a huge disconnect between the world of the criminologist and the institutional work of 
the ethics committee. This gap is important and revealing. At least part of the problem stems from the multi-disciplinary nature of ethics committees and the lack of knowledge or understanding academics working in other disciplines often have of criminology. Of course, many foundational works in criminology and the sociology of deviance evolved in a naturalistic and unruly manner and yet still managed to produce illuminating data and transformative theory. These researchers were not required to inform the police if they happened to witness a crime, and nor were they encouraged to conduct elaborate consent procedures before engaging with research participants (consider, for example, Thrasher, 1927; Polsky, 1967; Young, 1971). Somehow they managed to muddle through, and the results were positive. To the best of our knowledge no great harms accrued. The past of our discipline is not a barbarous past we should attempt to leave behind as we make our way inexorably to a civilizational ideal in which all the foibles and risks of human relationships have been removed. Qualitative social research forms an important part of our shared disciplinary past and we should do all we can to maintain a connection to it and ensure that it is not policed out of existence.

When conducting covert work as a nightclub doorman, it was imperative for Winlow (see Winlow, 2001; Winlow et al. 2001; Hobbs et al, 2003) to actively assume that identity and become involved in all of the incidents that fall within the remit of nightclub doormen. Of course, doormen, landlords and private security firms have nothing to gain by allowing a criminologist to assume such a role within their cultures. We can, of course, interview doormen and ask them about their occupational culture and their involvement in violent incidents, but becoming immersed in their culture, witnessing and reporting upon the actuality of violent incidents, and, essentially, 'seeing the world as they see it' (Berger, 1972), produces data of an entirely different order. Of course, things that are mundane and 
uninteresting to a nightclub doorman can be illuminating for a social researcher. Such events are often missing from interview data as foreground action tends to dominate conversation. Being there in the flesh can provide the observer with insights that would be unforthcoming if other methodologies were used. In interviews, for example, one might ask a doorman what happened on a particular evening at work. Often doormen will reply with 'nothing much', or 'it was another boring night'. Of course, their assessment is based upon their own experience of their work and the environment in which they conduct their work. However, when the bouncer says 'nothing happened', he is in fact quite wrong. 'Something' did happen, even if, from the bouncer's point of view, it was not particularly interesting (see Hobbs et al, 2003). For social researchers keen to accurately capture the social scene, accessing this hidden reality means that one must go deeper into the researched community.

Measham recently undertook 200 hours of ethnographic observation in Soho, London, between the hours of $6 \mathrm{pm}$ to $4 \mathrm{am}$, across twenty consecutive nights. The study, funded by Westminster Council (see Hadfield et al, 2014), sought to investigate the benefits and costs of the night time economy in Soho. Her presence on the street from dusk till dawn in all weathers allowed her the opportunity to get to know the characters who inhabited the area after dark - the touts, dealers, sex workers, homeless drinkers, beggars, taxi drivers, rickshaw cyclists, pickpockets and flower sellers - those who lingered long after the customers had left the theatres, bars and nightclubs. Over the course of the fieldwork she was able to build up a rapport with these various street inhabitants and begin to hear their stories. These various nocturnal habitués grew to trust her and gradually became willing to confide in her. Measham exposed herself to significant personal risks, and she witnessed or became aware of a wide range of crimes. However, it is only by taking on these challenges that we can access the rich data that in situ research can yield. It is only by developing personal relationships with groups 
of interest to criminologists that we can begin to refine our understanding of complex issues that lie beneath mere verbal recollections of the social scene. And, of course, if Measham had informed the police every time she witnessed or heard about a crime, her research project would have been over just as it was beginning to get underway. Conducting research projects of this kind takes time, and they are not without risk. However, there is no 'ethical' reason why we should effectively close off participant observation to researchers keen to take on the challenges of engaging with the world in this way (see Ancrum, 2012).

Of course many criminal groups remain almost totally inaccessible to criminological researchers. In such instances it may be necessary to use covert methods to generate data, and it is at this point that we need the thoughtful and considered judgement of our peers to determine how far the researcher can or should go in search of criminological knowledge. It is quite obviously counter-productive to deny ourselves knowledge of reality because researching that reality may necessitate the use of covert methods. We completely refute the suggestion that covert methods are necessarily unethical and in every instance harm the researched community. Of course, by demanding that all ethnographers utilise consent procedures the ethics committee is engaged in a subtle process of eradicating covert ethnography. When used judiciously, covert ethnography has great utility for criminology. It is only in the current context of panoramic liberalism - in which we assume that denying individuals all available information is necessarily 'unethical' - that we have formed the view that covert research is wrong and must be dispensed with. Perhaps more than any other methodology covert ethnography has the capacity to reveal hidden worlds. It enables the criminological community to leave behind the confines of the campus and become conversant with the lifeworlds of our most marginalised communities. However, in British criminology it has almost disappeared. 
Other forms of qualitative research are also under pressure. Today virtually all researchers who engage with human subjects are required to use consent forms. These forms usually outline the research project, describe how the words of the interviewee will be used, indicate that the interviewee can withdraw from the interview at any time, and provide the interviewee with contact information for a supervisor working at the university who they can contact if they feel uncomfortable about what has taken place. In many respects this process is unproblematic, but we should also note that such formalities immediately disturb social behaviour and deprive it of a degree of authenticity. If we are interviewing probation officers, an occupational group with direct experience of bureaucracy and with little to lose when engaging with academic researchers, then it's likely that their commentary will not be hugely affected by the presence of consent forms. However, if we are interviewing violent criminals in a non-custodial setting, and if we intend to ask them about their own involvement in violent crime, then the consent procedure quite clearly has the potential to disrupt and potentially ruin the research project. Of course, some research contacts cannot read and write and feel ill-at-ease in the presence of such forms. They are uncomfortable with 'authority' as most of their encounters with it have been negative. They have encountered forms in police stations and prisons, and associate such formalities with those settings. What chance does the researcher have of getting a violent criminal to talk honestly and openly about his crimes in such circumstances?

In the example alluded to above, Measham applied for ethical approval for annual surveys, ethnographic observations and stakeholder interviews in South London gay clubs as part of her broader portfolio of research on dance drug use in dance music venues. The project hinged on a decision by a university ethics committee to demand the written informed 
consent of every customer in a nightclub (which often held around 1000) before the project could be granted ethical approval and data collection could go ahead. Of course, the management of the nightclub would have immediately withdrawn its support for the research if such a strategy was adopted, and the research project would then have to be abandoned. It would be almost impossible to go through a consent procedure with one thousand clubbers in the space of one night, and totally impossible to do this before moving on to the actual business of researching drug-users and club-goers. And, of course, those attending the venue had no interest in such matters. They wanted to get into the club as quickly as possible so that they could enjoy their night out. Forcing clubbers to go through this procedure would've ensured many club-goers simply disengaged and went elsewhere. To complicate matters further still, this was a nightclub popular with men who have sex with other men. Understandably, many of the club's patrons would have been unwilling to leave a record that they had been in attendance. An absurd judgement by an ethics committee keen to enforce the rules almost destroyed a research project that held great promise. Edicts such as this indicate quite clearly just how detached some ethics committees are from the actual business of social scientific research.

Ethics committees with a little more experience in dealing with research proposals put forward by criminologists often accept that, in such circumstances, a verbal consent procedure can be used instead of the usual forms. In verbal consent procedures the researcher simply talks through the content of the consent form and outlines for the interviewee key points of note. Again, this can work, but it can also alienate respondents and encourage them to withdraw. When conducting ethnographic work with violent offenders (Winlow), or with customers in the night time economy (Measham), a huge amount of effort is needed simply to get the respondent into a position where it is possible to ask research-based questions. The 
researcher needs the interviewee to feel comfortable with his or her presence. If the researcher then pulls out a recording device and adopts the formal language of the university, events can quickly take a turn for the worse. And further, we should not simply assume that it will be easy to come across another research contact of this type. Many ethnographers conduct interviews as part of their broader projects, and snowball sampling is often used to develop a workable sample. The ethnographer needs gatekeepers. He or she needs to develop and maintain workable relationships with key contacts. Even verbal consent procedures have the potential to impede data gathering and disrupt budding research relationships.

Understandably enough, many active criminals distrust those who carry forms and ask for signatures. They have learnt to clam up when faced with individuals from an alien culture who talk about research projects, outputs and complaints procedures. It is not that the interviewee's initial reticence cannot be overcome, but considerable effort needs to be applied to maintain affective research relationships in the presence of such formalities, and inevitably some research contacts will find the process too off-putting and decide to withdraw or otherwise withhold information. Our claim is not that research that fully subscribes to the logic of fully informed consent has little value. Such research can be of considerable use. However, we must accept that covert participant observation, or ethnographic research that bypasses the formalities of informed consent procedures, is better suited to capturing something approaching authenticity, or at least a reality less disturbed by the presence of a researcher.

\section{Conclusion: Towards an embodied professional ethics}

To us it seems obvious that criminologists must mount a determined campaign to defend ourselves against forces that have the potential to curtail the production of criminological 
knowledge. We must defend qualitative and in situ research methodologies and fight for the right to engage with the world as we find it. We must do all we can to ensure that, as much as possible, market pragmatism is dispensed with and proper ethical consideration of research problems becomes the focus of attention.

\section{Research questions}

1. According to the authors, how has the institutional ethics committee changed in recent years?

2. How might informed consent procedures, both written and verbal, disrupt ethnographic research encounters?

\section{Case example:}

"Gordon... begins to kick the man and is joined in this by Frankie and Matty. They aim kicks at the man's head, the way you would shape up to strike a football with utmost force. Frankie is swearing, calling the man a bastard. I see the man role into the foetus position and cover his head with his hands. Matty... is also swearing and is now raising his foot to stamp on the man's head. Frankie and Matty, and now Kevin, kick the man for a while longer and then ease up for a moment. The wounded man, lying on the ground, has stopped moving and I consider seriously the possibility that they've killed him. However, he then sparks back into life, rolls onto his other side, re-covers his head and the kicking recommences. Against all instinct I tell the men to stop. I don't want to, but I feel compelled. I know what doing this can mean. I am not naïve about what these men can do. My stomach is turning as I say, leave him alone, he's had enough... The Monday following this incident I was in the more comfortable confines of Durham University. I spoke to my supervisor and we agreed it was time to start negotiating my withdrawal from the field" (Winlow, 2001: 157-159). 
Questions:

1. For the researcher, what was the most ethical course of action in this case?

2. Can there ever be a reasonable justification for conducting covert research among criminal groups of this sort?

3. If covert research is judged fundamentally 'unethical', how will this judgement affect the production of criminological knowledge?

\section{Summary}

In this chapter we have argued that institutional ethics committees are now less concerned with 'ethics' than they are with defending the institution from possible litigation and negative attention and commentary. The infiltration of market concerns into the realm of ethical deliberation has the potential to shift the trajectory of British criminology and deprive generations of scholars forms of knowledge that spring from participant observation, covert ethnography and other forms of qualitative and in situ social research.

Key readings:

Measham, F., Wood, D., Dargan, P. and Moore, K. (2011), 'The Rise in Legal Highs: Prevalence and patterns in the use of illegal drugs and first and second generation 'legal highs' in south London gay dance clubs', Journal of Substance Use, 16 (4): 263-272. In this article Measham and colleagues discuss their work in south London dance clubs and reflect upon some of the problems associated with generating data in such a setting.

Winlow, S. and Hall, S. (2012) 'What is an 'Ethics Committee'? Academic Governance in an Epic of Belief and Incredulity', British Journal of Criminology, 52 (2): 400-416. In this 
article, using Lacanian psychoanalysis, Winlow and Hall offer a critique of postmodernism, the marketization of the university and contemporary institutional ethics committees.

References

Ancrum, C. (2012) 'Stalking the Margins of Legality: Ethnography, Participant Observation and the Postmodern Underworld' in S. Winlow and R. Atkinson (eds) New Directions in Crime and Deviancy, London: Routledge

Becker, H. (1963) Outsiders, New York: The Free Press

Bell, D. (2014) 'What is Liberalism?', Political Theory, DOI: 10.1177/0090591714535103

British Society of Criminology (2006) Code of Ethics for Researchers in the Field of Criminology, http://www.britsoccrim.org/docs/CodeofEthics.pdf

Currie, E. (2007) 'Against Marginality: Arguments for a Public Criminology', Theoretical Criminology 11(2): 175-90

Ditton, J. (1979) Contrology: Beyond the New Criminology, London: Macmillan Berger, J. (1972) Ways of Seeing, Harmondsworth: Penguin

Ellis, A. (2015) Men, Masculinities and Violence: An Ethnographic Study, London: Routledge

Goulder, A. (1962) 'Anti-Minotaur: The Myth of a Value-Free Sociology', Social Problems, 9, 3: 199-213

Hadfield, P., Measham, F., Sharples, S. and Bevan, T. (2014), The Evening and Night-time Economy in London's West End: A Behavioural Audit and Case Studies in 10 Locations, Final Report to the City of Westminster, www.philhadfield.co.uk. Hall, S. (2012) Theorizing Crime and Deviance: A New Perspective, London: Sage 
Hall, S. and Winlow, S. (2015) Revitalizing Criminological Theory: Towards a New UltraRealism, London: Routledge

Hall, S., Winlow, S. and Ancrum, C. (2008) Criminal Identities and Consumer Culture: Crime, Exclusion and the New Culture of Narcissism, Cullompton: Willan

Hobbs, D., Hadfield, P. Lister, S. and Winlow, S. (2003) Bouncers: Violence and Governance in the Night-time Economy, Oxford: Oxford University Press.Horsley, M. (2014) 'The Death of the Deviance and the Stagnation of $20^{\text {th }}$ Century Criminology' in M. Dellwing, J. Kotarba and N. Pino (eds) The Death and Resurrection of Deviance, London: Palgrave Macmillan

Matthews, R. (2009) 'Beyond 'so what?' criminology: Rediscovering realism', Theoretical Criminology 13(3): 341-362.

Matthews, R. (2015) Realist Criminology, London: Palgrave Macmillan.

Measham, F., Wood, D., Dargan, P. and Moore, K. (2011), 'The Rise in Legal Highs: Prevalence and patterns in the use of illegal drugs and first and second generation 'legal highs' in south London gay dance clubs', Journal of Substance Use, 16 (4): 263-272 Polsky, N. (1967) Hustlers, Beats and Others, New York: Anchor. Roberts, H. (1981) Doing Feminist Research, London: Routledge \& Kegan Paul. Smart, C. (2003) 'Feminist Approaches to Criminology or Postmodern Woman meets Atavistic Man', Crime: Critical concepts in sociology, London: Routledge, pp. 153-169. ?? reproduced in that book? First published in 1991 in Feminist Perspectives in Criminology edited by Gelsthorpe, L. and Morris, A. (Milton Keynes: Open University Press).

Smith, O. (2014) Contemporary Adulthood and the Night-Time Leisure Economy, London: Palgrave Macmillan

Stanley, L. and Wise. S. (2002) Breaking out again: Feminist ontology and epistemology, London: Routledge. 
Thrasher, F. (1927) The Gang, Chicago: University of Chicago Press

Winlow, S. (2012) 'Is it OK to talk about capitalism again? Or, Why Criminology must take a leap of faith' in S. Winlow and R. Atkinson (eds) New Directions in Crime and Deviancy, London: Routledge

Winlow, S. (2001) Badfellas: Crime, Tradition and New Masculinities, Oxford: Berg Winlow, S. and Hall, S. (2012) 'What is an 'Ethics Committee'? Academic Governance in an Epic of Belief and Incredulity', British Journal of Criminology, 52 (2): 400-416

Winlow, S., Hall, S., Briggs, D. and Treadwell, J. (2015) Riots and Political Protest: Notes from the Post-Political Present, London: Routledge

Winlow, S., Hobbs, D., Lister, S., and Hadfield, P. (2001) 'Get Ready to Duck: Bouncers and the realities of ethnographic research on violent groups', British Journal of Criminology, 41(3), 536-548

Young, J. (1971) The Drugtakers, London: Paladin 